\title{
Hospitalizations and Mortality of Individuals with Dementia: Evidence from Czech National Registers
}

\author{
Hana Marie Broulikova a,b,c,* ${ }^{\mathrm{a}, \text { Marketa Arltova }}{ }^{\mathrm{b}}$, Marie Kuklova ${ }^{\mathrm{c}}$, Tomas Formanek ${ }^{\mathrm{c}}$ \\ and Pavla Cermakova ${ }^{\mathrm{c}, \mathrm{d}, \mathrm{e}}$ \\ ${ }^{a}$ Faculty of Science, Vrije Universiteit Amsterdam, Amsterdam, Netherlands \\ ${ }^{\mathrm{b}}$ Faculty of Informatics and Statistics, University of Economics, Prague, Czech Republic \\ ${ }^{\mathrm{c}}$ National Institute of Mental Health, Klecany, Czech Republic \\ ${ }^{\mathrm{d}}$ Third Faculty of Medicine, Charles University Prague, Prague, Czech Republic \\ ${ }^{\mathrm{e}}$ Second Faculty of Medicine, Charles University Prague, Prague, Czech Republic
}

Accepted 24 March 2020

\begin{abstract}
.
Background: Facing an increasing prevalence of dementia, the Czech Republic is developing a new nationwide strategy for the management and prevention of dementia. Lack of evidence about characteristics of individuals with dementia in the country is a major obstacle.

Objective: The study aimed to 1) characterize individuals with dementia, 2) compare their mortality with the general population, and 3) analyze differences in survival between different dementia disorders.

Methods: The study capitalizes on two nationwide registers in the Czech Republic, from which information about individuals who were hospitalized with dementia or died from it between 1994 and 2014 was retrieved. Standardized intensity of hospitalizations was calculated for each year, mortality was studied using standardized mortality ratio, life-tables, KaplanMayer curves, and Cox proportional hazard models.

Results: Standardized intensity of hospitalizations for dementia increased more than 3 times from 1994 to 2014. Standardized mortality ratio was 3.03 (95\% confidence interval 2.97-3.08). One-year survival rate was $45 \%$ and five-year survival rate $16 \%$. Vascular dementia was the most common type of dementia disorders and was associated with higher hazard of death than Alzheimer's disease, even after adjusting for sociodemographic and clinical covariates (hazard ratio 1.04; 95\% confidence interval 1.02-1.05).

Conclusion: The study provides estimates on demographic characteristics and mortality of the Czech hospitalized dementia population, which have not been so far available and which are unique also in the context of the entire region of Central and Eastern Europe.
\end{abstract}

Keywords: Alzheimer's disease, Czech Republic, dementia, hospitalization, mortality, population characteristics, registries

\section{INTRODUCTION}

The Czech population has been significantly aging [1]. The drastic improvement in health following the

\footnotetext{
*Correspondence to: Hana M. Broulikova, PhD, Vrije Universiteit Amsterdam, De Boelelaan 1105, 1081 HV Amsterdam, The Netherlands. Tel.: +420 607920 481; E-mail: h.m.broulikova @vu.nl.
}

fall of communism in 1989 led to an increase in life expectancy in men from 68 to 76 years and in women from 75 to 82 years between 1990 and 2017 [2]. The share of people above 65 years of age grew from $13 \%$ to $19 \%$ in the same period [2]. As a result, the Czech Republic is facing challenges of increasing prevalence of age-related disorders, such as dementia. 
The large associated costs, driven mainly by informal caregiving and social care, create a pressure on household as well as public budgets [3, 4]. For the Czech Republic, Broulíková and colleagues estimated that in 2017 the lifetime costs per a woman developing dementia at the age of 70 years amounted to over 200,000 Euro, out of which over $90 \%$ was consumed by informal care. The costs are decreasing with age and are generally lower for men due to a shorter life expectancy [5]. To put this burden in the context of Czech economic situation, the average annual salary amounted to 13,450 Euro in 2017 [6]. The World Health Organization (WHO) claims dementia a public health priority and encourages individual countries to formulate detailed policies addressing the complex needs of this population and endorsing prevention [3, 7]. The Czech Republic recently joined this initiative, developing a new national strategy for dementia.

An important obstacle in creating such a public policy plan is a lack of epidemiological evidence. Some countries such as Sweden, Norway, Denmark, France, Spain, Austria, and South Korea [8-14] maintain national registers collecting and regularly analyzing data about people diagnosed with dementia that serve as a basis for policy and system adjustment. Central and Eastern Europe (CEE) countries, including the Czech Republic, do not possess such a systematic source of data that is specific for dementia [15]. A need to improve epidemiological evidence about dementia in CEE has been explicitly formulated in literature [16]. The goal of the present study is to bridge the information gap surrounding dementia in the Czech Republic. Capitalizing on data from two nationwide administrative health registers collected during a twenty-one-year period, we aimed to 1) characterize individuals who were either hospitalized with dementia or had dementia diagnosis as a death cause in their death certificate, 2) compare their mortality with the general population, and 3) study differences in survival between different dementia disorders among those who were hospitalized with dementia diagnosis.

\section{METHODS}

\section{Source of data}

We analyzed data spanning the period from January 1994 until December 2014 retrieved from two national registers maintained by the Czech Institute of Health Information and Statistics. First, the National
Register of Hospitalized Patients (NRHP) provided data about all hospitalizations, registered at discharge in all Czech hospitals. The record of each hospitalization includes the main diagnosis, up to five additional diagnoses, and sociodemographic characteristics of the patient. Second, the National Register of Deaths (NRD) encompassed all deaths in the country and their causes. Both registers use the International Classification of Diseases 10 (ICD 10) coding [17]. The registers were merged using a unique personal identifier, with the data having been pseudoanonymized beforehand. This study was approved by the Ethical Committee at the National Institute of Mental Health in Klecany, Czech Republic.

\section{Dementia}

Dementia was identified in the NRHP or NRD if Alzheimer's disease (AD; ICD 10 code G30 or F00), vascular dementia (VaD; F01), unspecified dementia (F03), dementia with Lewy bodies (DLB; G31.8), Parkinson's disease with dementia (PDD; F02.3), and frontotemporal dementia (FTD; G31.0) appeared as the main or additional diagnosis. In case different types of dementia disorders appeared during one hospitalization at the same time, we kept the one listed on the higher position (the highest position is the main diagnoses, followed by additional diagnosis 1 , additional diagnosis 2, etc.). However, if unspecified dementia appeared on a higher position than other dementia diagnosis, we kept the one on the lower position because it is more specific. Fifteen percent of people in our sample were diagnosed with two or more different dementia disorders during the observed period (data not presented in tables). As our method on defining diagnoses is arbitrary, we performed three sensitivity analyses to test the robustness of our approach: First, we introduced a mixed dementia category for those who obtained multiple dementia diagnoses during their first hospitalization (sensitivity analysis 1). Second, we considered the highest dementia diagnosis even if it was unspecified dementia (sensitivity analysis 2). Third, we excluded all people who were given multiple dementia diagnoses during the observed period (sensitivity analysis 3 ).

\section{Analytical samples}

We conducted the main analyses using four different samples, which we refer to as "hospitalizations", "hospitalized cohort", "deceased cohort", and "2014 
cohort". The sample hospitalizations contains hospitalizations where dementia appears as a diagnosis; i.e., readmissions of the same individual are included. The hospitalized cohort contains incident cases of dementia. The deceased cohort contains individuals with dementia who died during the observed period. The 2014 cohort contains individuals who have ever been diagnosed with dementia and lived (and may have died) at some point in 2014.

The samples were arrived at as follows: Merging the NRHP (49,148,789 observations) with the NRD $(2,281,623)$, we identified 193,226 individuals with dementia diagnosis either obtained during hospitalization in NRHP or filled out as a death cause in NRD. Then we searched for all their hospitalizations $(1,665,496)$ to collect data about comorbidities. After retrieving the information about comorbidities, we retained 345,462 observations consisting of hospitalizations including dementia as diagnosis and all hospitalizations of individuals identified only in NRD. Subsequently, observations with missing information about sex $(8)$ or incorrect date of death $(1,186)$ were deleted. To retain ages typical for dementia, we further restricted this intermediate dataset to individuals aged at least 65 years at their first hospitalization for dementia and not more than 100 years at the end of follow-up or their death $(29,993$ observations excluded).

The resulting dataset that counted 314,335 observations was used to derive the deceased cohort (145,293; keeping those who died), the 2014 cohort (43,019; those who lived in 2014), and hospitalizations (293,508; hospitalizations where dementia appears as a diagnosis). Finally, the hospitalized cohort was derived from hospitalizations as follows: As the hospitalized cohort contains only incident cases, we considered first five years in our data (1994$1998)$ as a wash out period. We removed $(31,333)$ observations of 22,160 individuals who were first hospitalized with dementia diagnosis before 1999 . Then, only the first hospitalization of each individual remaining in the sample was preserved $(150,311)$. Figure 1 depicts the process of samples creation.

\section{Covariates}

Following characteristics were obtained from the NRHP about the hospitalized cohort at the time of their first hospitalization: age, sex (men versus women), civil status (partner versus no partner versus unknown), type of facility (general hospital versus long term care facility versus psychiatric hospital ver- sus other), reason for admission (treatment versus diagnosis versus other), care plans after the discharge (none versus outpatient versus institutional versus unknown), and region of the hospital. In addition, we created a Charlson comorbidity index (CCI) [18], which is a predictor of mortality [19] and an indicator of overall comorbidity used for patients with dementia [20]. The CCI is defined as a sum of 17 diseases. The disease was counted if the respective ICD 10 code, used according to Sundararajan et al. [21], appeared at least once as the main or additional diagnosis in the NRHP before the diagnosis of dementia. Every individual received automatically 1 point for the diagnosis of dementia. The diseases were weighted according to a previously established method [18]. We further report age at death and the most prevalent causes of death, coded according to ICD 10. These characteristics of the deceased cohort were retrieved from the NRD.

\section{Statistical analysis}

\section{Aim 1: Characteristics of individuals with dementia}

First, we present standardized intensity of hospitalizations for dementia. We analyzed only AD, $\mathrm{VaD}$, and unspecified dementia as other types of dementia disorders appeared rarely. Dividing the number of individuals hospitalized with dementia by the mid-year population of the Czech Republic in each year, the intensity of hospitalization was calculated for each five-year age interval (65-69, 70-74, 75-79, 80-84, 85-89, 90-94, 95+) according to sex. Next, it was multiplied by the European standard population (EUROSTAT) and summed up for all age groups, giving the final standardized intensity of hospitalizations per 100,000 inhabitants. We also report the figure per dementia disorder.

Second, we present descriptive characteristics of the hospitalized cohort as mean \pm standard deviation (SD) for continuous variables with normal distribution, median and interquartile range (IQR) for skewed continuous variables and frequency $(\mathrm{n} ; \%)$ for categorical variable. We compared the characteristics between types of dementia disorders $(\mathrm{AD}, \mathrm{VaD}$, unspecified dementia, DLB, PDD, and FTD), using analysis of variance (ANOVA) for continuous variables with normal distribution, Kruskal-Wallis test for skewed continuous variables and chi-square test for categorical ones. Third, we present descriptive 


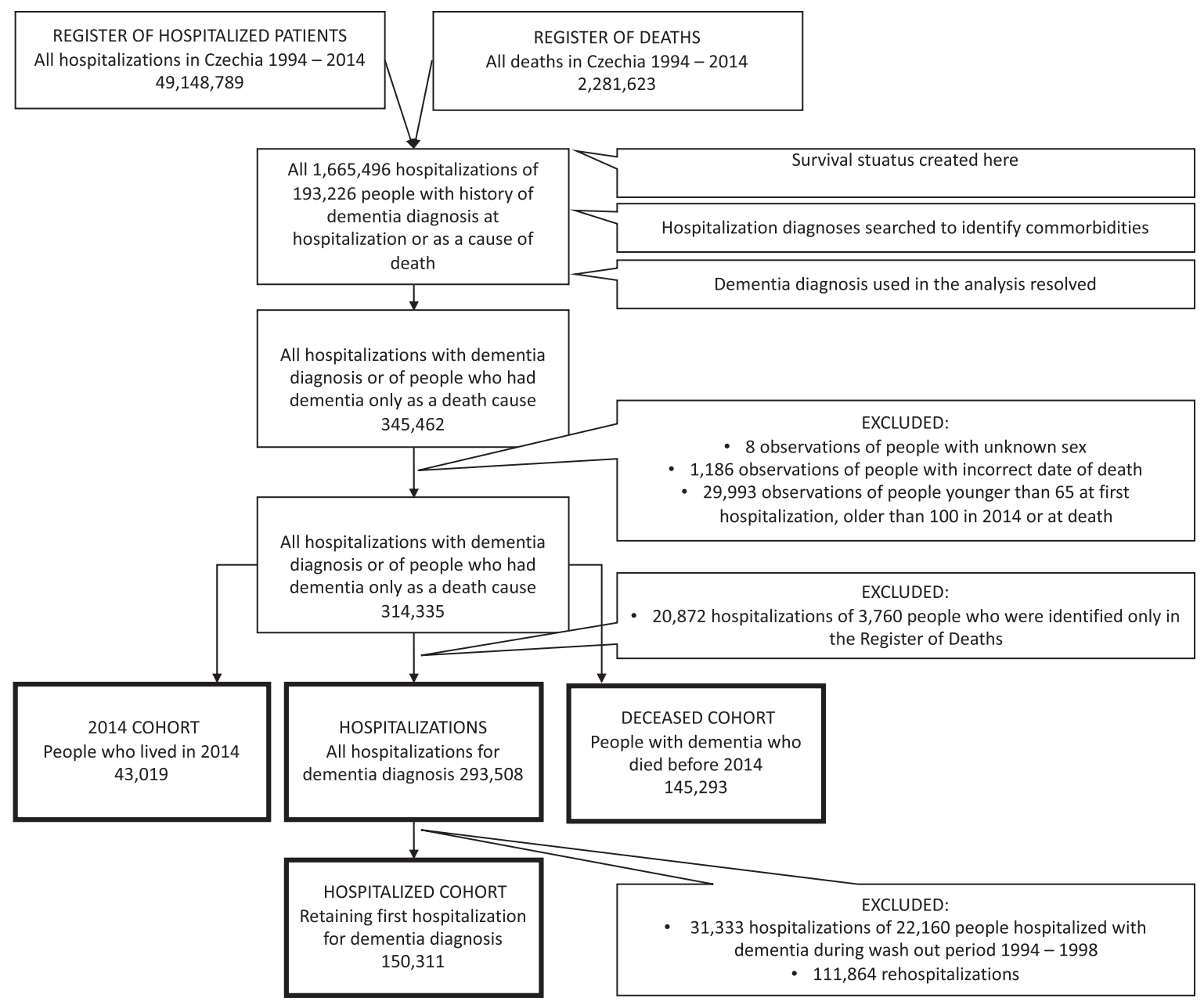

Fig. 1. Samples creation flow chart.

characteristics of the deceased cohort as mean $\pm \mathrm{SD}$ or frequency, where appropriate.

\section{Aim 2: Comparison of mortality of dementia patients with the general population}

We calculated the standardized mortality ratio (SMR) for the year 2014, using the 2014 cohort. This measure compares the mortality in people with dementia with the mortality observed in the general population, adjusting for age and sex. We used five-year age intervals $(65-69,70-74,75-79,80-84$, $85-89,90-94,95-100)$ and two sex categories. The number of deaths and the Czech mid-year population in 2014 was retrieved from the Czech Statistical Office [22]. We provide SMR only for the most recent year as the potential developments in mortality patterns would be blurred by changes in diagnos- tic practices that likely occurred during the observed period.

\section{Aim 3: Differences in survival between different dementia disorders}

We further analyzed survival of the hospitalized cohort. We used life tables for the analysis of survival rates and Kaplan-Meier curves to estimate median survival time, with log-rank tests assessing differences between types of dementia disorders. We employed Cox proportional hazards regression models to estimate hazard ratio (HR) with $95 \%$ confidence intervals (CI) for the associations of type of dementia disorder (AD, VaD, unspecified, DLB, PDD, and FTD) with all-cause mortality. The models were adjusted for age, sex, and CCI (Model 1) and also for type of facility, civil status, reason for admission, 

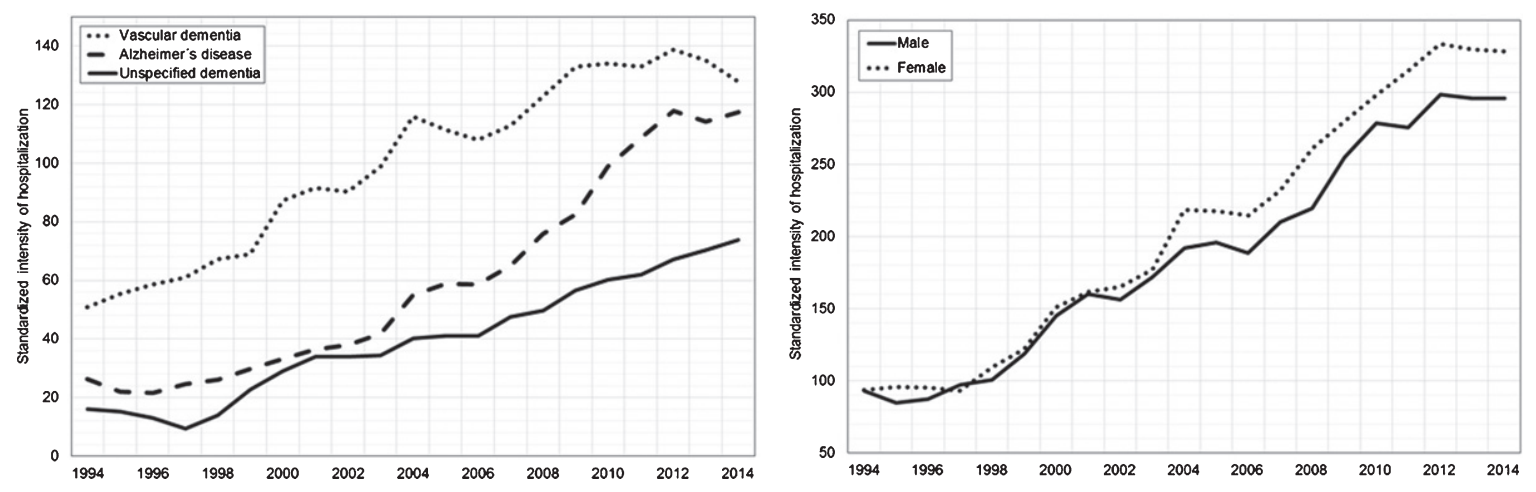

Fig. 2. Standardized intensity of hospitalizations for dementia by sex and type of dementia disorder.

planned care, and region (Model 2). These covariates were chosen based on literature as sociodemographic and clinical characteristics associated with mortality in people with dementia [23-27]. The individuals in the hospitalized cohort were followed from the discharge from their first hospitalization for dementia until 31 December 2014 or death, whichever came first. We used the date of discharge rather than date of admission to be in line with international registerbased studies on this topic [23-27] and because it is a more reliable information with no missing values.

\section{RESULTS}

During the observed period, 293,508 hospitalizations for dementia occurred. The standardized intensity of dementia hospitalizations increased more than three times from 1994 to 2014, adjusting for age in 5-year age intervals, and for sex. At the beginning of the follow-up period in 1994, it was similar for women (94 per 100,000 inhabitants) and men (93 per 100,000 inhabitants); however, the intensity of hospitalizations increased until 2014 to a greater extent in women (328 per 100,000 inhabitants) than men (296 per 100,000 inhabitants). The most common type of dementia disorder was $\mathrm{VaD}$ throughout the whole follow-up period, followed by AD and then unspecified dementia. The intensity of hospitalizations for $\mathrm{VaD}$ increased 2.5 times during the follow-up (from 51 to 128 hospitalizations per 100,000 inhabitants), while for AD 4.5 times (from 26 to 118 hospitalizations per 100,000 inhabitants) and for unspecified dementia even 4.6 times (from 16 to 74 hospitalizations per 100,000 inhabitants). The greatest intensity of hospitalization was in the age group 80-84, then 75-79 and 85-89, while the lowest were observed in the 95+, 65-69, then 70-74 and 90-94 categories. Figure 2 depicts the changes in standardized intensity of hospitalization for different diagnoses and sex.

Table 1 presents characteristics of the hospitalized cohort. The majority of them were women $(66 \%)$ and they were on average 81 years old when first hospitalized for dementia. The most common type of dementia disorder was $\mathrm{VaD}(49 \%)$, followed by $\mathrm{AD}(27 \%)$, and unspecified dementia (22\%). Other dementia diagnoses were rare (PDD 0.9\%; DLB 0.7\%; FTD 0.6). The group with DLB was the youngest one and the group with $\mathrm{AD}$ consisted of most women. Table 2 reports results concerning deaths within the deceased cohort. The mean age at death ranged from 79.2 (76.9) in women (men) with DLB to 83.9 (81.0) years in individuals with unspecified dementia. The most frequent cause of death was chronic ischemic heart disease (15\%) followed by atherosclerosis (13\%). Only $11 \%$ of the deceased cohort had dementia diagnosis in their death certificate, of whom almost half had AD (47\%).

People with dementia demonstrated three times higher mortality than general population, adjusting for age and sex (SMR $=3.03$; 95\% CI 2.97-3.08). Figure 3 compares proportions of deaths in the 2014 cohort and the general 2014 population for five-year age intervals. Two-sample z-test for the difference between proportions shows significantly higher proportions of deaths in the study cohort against the general population in age groups over 80 years.

The median survival time of the hospitalized cohort was 264 days (95\% CI 259-269) while the median follow-up time reached 203 days (range 0 to 16 years, IQR 2.2 years; reversed Kaplan-Meier 2,056 days). During the whole follow-up period, 120,386 individuals $(80 \%)$ died. Further, one-year survival rate for all dementia disorders together was $45 \%$ 
Table 1

Characteristics of the hospitalized cohort $(n=150,311)$

\begin{tabular}{|c|c|c|c|c|c|c|c|c|}
\hline & $\begin{array}{l}\text { Any dementia } \\
(n=150,311)\end{array}$ & $\begin{array}{c}\mathrm{AD} \\
(n=40,075)\end{array}$ & $\begin{array}{c}\mathrm{VaD} \\
(n=74,246)\end{array}$ & $\begin{array}{l}\text { Unspecified } \\
(n=32,823)\end{array}$ & $\begin{array}{c}\text { DLB } \\
(n=984)\end{array}$ & $\begin{array}{c}\text { PDD } \\
(n=1303)\end{array}$ & $\begin{array}{c}\text { FTD } \\
(n=880)\end{array}$ & $p$ \\
\hline Age, mean \pm SD & $80.9 \pm 6.8$ & $79.9 \pm 6.6$ & $81.5 \pm 6.8$ & $81.3 \pm 7.1$ & $75.7 \pm 7.1$ & $78.0 \pm 6.4$ & $77.2 \pm 7.2$ & $<0.001$ \\
\hline Women, $n(\%)$ & $99,661(66.3)$ & $27,516(68.7)$ & $48,545(65.4)$ & $22(67.1)$ & $527(53.6)$ & $577(4$ & $474(53.9)$ & $<0.001$ \\
\hline \multicolumn{9}{|l|}{ Type of facility, $n(\%)$} \\
\hline General hospital & $92,618(61.6)$ & $25,095(62.6)$ & $44,823(60.4)$ & $19,982(60.9)$ & $831(84.5)$ & $1,098(84.3)$ & 789 (89.7) & $<0.001$ \\
\hline Long-term care facility & $26,559(17.7)$ & $4,844(12.1)$ & $14,173(19.1)$ & $7,234(22.0)$ & $131(13.3)$ & $137(10.5)$ & $41(4.7)$ & \\
\hline Psychiatric hospital & $28,954(19.3)$ & $9,068(22.6)$ & $14,543(19.6)$ & $5,237(16.0)$ & $13(1.3)$ & $49(3.8)$ & $44(5.0)$ & \\
\hline Other & $2,179(1.4)$ & $1,068(2.7)$ & $707(1.0)$ & $370(1.1)$ & $9(0.9)$ & $19(1.5)$ & $6(0.7)$ & \\
\hline \multicolumn{9}{|l|}{ Civil status, $n(\%)$} \\
\hline With partner & $5,790(30.5)$ & $14,154(35.3)$ & $20,861(28.1)$ & $9,238(28.1)$ & $465(47.3)$ & $706(54.2)$ & $366(41.6)$ & $<0.001$ \\
\hline & 9 & 22,293 & 46,52 & & 456 & 511 & 458 & \\
\hline Unknown & .2) & $3,628(9.1)$ & $6,864(9.2)$ & $3,164(9.6)$ & $63(6.4)$ & $86(6.6)$ & $56(6.4)$ & \\
\hline \multicolumn{9}{|c|}{ Reason for admission, $n(\%)$} \\
\hline Treatment & $141,371(94.1)$ & $37,510(93.6)$ & $70,077(94.4)$ & 30,919 (94.2) & $848(86.2)$ & $1,209(92.8)$ & 809 (91.9) & $<0.001$ \\
\hline Diagnosis & $4,656(3.1)$ & $1,445(3.6)$ & $1,859(2.5)$ & $1,174(3.6)$ & $58(5.9)$ & $68(5.2)$ & $52(5.9)$ & \\
\hline Other & & $1,120(2.8)$ & $2,310(3.1)$ & $730(2.2)$ & & & & \\
\hline \multicolumn{9}{|l|}{ Planned care, $n(\%)$} \\
\hline None & & & & & $134(13.6)$ & $208(16.0)$ & $108(12.3)$ & $<0.001$ \\
\hline Outpatient & $60,768(40.4)$ & $17,570(43.8)$ & $27,632(37.2)$ & $13,836(42.2)$ & $590(60.0)$ & $636(48.8)$ & $504(57.3)$ & $<0.001$ \\
\hline Institutional & $44,310(29.5)$ & $11,158(27.8)$ & $22,201(29.9)$ & $10,079(30.7)$ & $222(22.6)$ & $415(31.8)$ & $236(26.8)$ & $<0.001$ \\
\hline Unknown & $8,698(5.8)$ & $2,260(5.6)$ & $4,768(6.4)$ & $1,556(4.7)$ & $28(3.9)$ & $44(3.4)$ & $32(3.6)$ & $<0.001$ \\
\hline CCI, median (IQR) & $2(3)$ & $2(2)$ & $2(2)$ & $2(2)$ & $2(2)$ & $2(3)$ & $2(3)$ & $<0.001$ \\
\hline
\end{tabular}

AD, Alzheimer's disease; VaD, vascular dementia; DLB, dementia with Lewy bodies; PDD, Parkinson's Disease with dementia; FTD, frontotemporal dementia; SD, standard deviation; IQR, interquartile range; CCI, Charlson comorbidity index. $p$ values are derived from analysis of variance (age), Kruskal-Wallis test (CCI), or chi-square test (categorical variables).

Table 2

Characteristics of the deceased cohort $(n=145,293)$

\begin{tabular}{lr}
\hline Characteristic & \multicolumn{1}{c}{ Value } \\
\hline Age at death, mean \pm SD for women (men) & \\
Any dementia & $83.5 \pm 6.5(80.7 \pm 6.7)$ \\
AD & $82.2 \pm 6.4(80.2 \pm 6.5)$ \\
VaD & $83.9 \pm 6.4(81.0 \pm 6.7)$ \\
Unspecified & $84.1 \pm 6.5(80.9 \pm 6.9)$ \\
PDD & $80.8 \pm 6.4(78.9 \pm 5.9)$ \\
DLB & $79.2 \pm 7.9(76.9 \pm 6.6)$ \\
FTD & $81.1 \pm 7.3(77.5 \pm 7.0)$ \\
Cause of death & \\
Chronic ischemic heart disease & $21,135(14.5)$ \\
Atherosclerosis & $18,998(13.1)$ \\
Cerebral atherosclerosis & $10,748(7.4)$ \\
Stroke & $10,185(7.0)$ \\
Dementia & $16,230(11.2)$ \\
Other & $67,997(46.8)$ \\
\hline
\end{tabular}

$\mathrm{SD}$, standard deviation; AD, Alzheimer's disease; VaD, vascular dementia; PDD, Parkinson's disease with dementia; DLB, dementia with Lewy bodies; FTD, frontotemporal dementia.

and five-year survival rate $16 \%$ (Table 3). Individuals with DLB and FTD had the highest survival rates (DLB: one-year 65\% and five-year 36\%; FTD: oneyear $66 \%$ and five-year $33 \%$ ), while those with $\mathrm{VaD}$ had the lowest survival rates (one-year $42 \%$ and fiveyear 14\%). DLB patients survived the longest and those with $\mathrm{VaD}$ the shortest; using log-rank test, we found the differences between the dementia disorders statistically significant $(p<0.001)$.

Individuals with $\mathrm{VaD}$ and unspecified dementia had higher hazards of death in comparison to those with AD (VaD: HR 1.16; 95\% CI 1.14-1.18; unspecified dementia: HR 1.07; 95\% CI 1.05-1.09; Table 3, Model 0). On the contrary, DLB as well as FTD patients had lower hazards of death than AD (DLB: HR 0.62; 95\% CI 0.58-0.67; FTD: HR 0.63; 95\% CI $0.58-0.69$ ). There was no difference in risk of death between PDD and AD. Adjustment for covariates did not change the associations to a great extent, except for HR of unspecified dementia that became close to unity and was not longer greater than AD (Table 3, Model 1 and 2). These results did not greatly differ in sensitivity analyses (Table 4). Those with mixed dementia had higher risk of death than AD patients (fully adjusted HR 1.21 ; 95\% CI 1.17-1.26, sensitivity analysis 1 ).

\section{DISCUSSION}

In this nationwide, longitudinal, register-based study encompassing 150,000 people with dementia over the period of 21 years, we found that the intensity of dementia hospitalizations more than tripled 


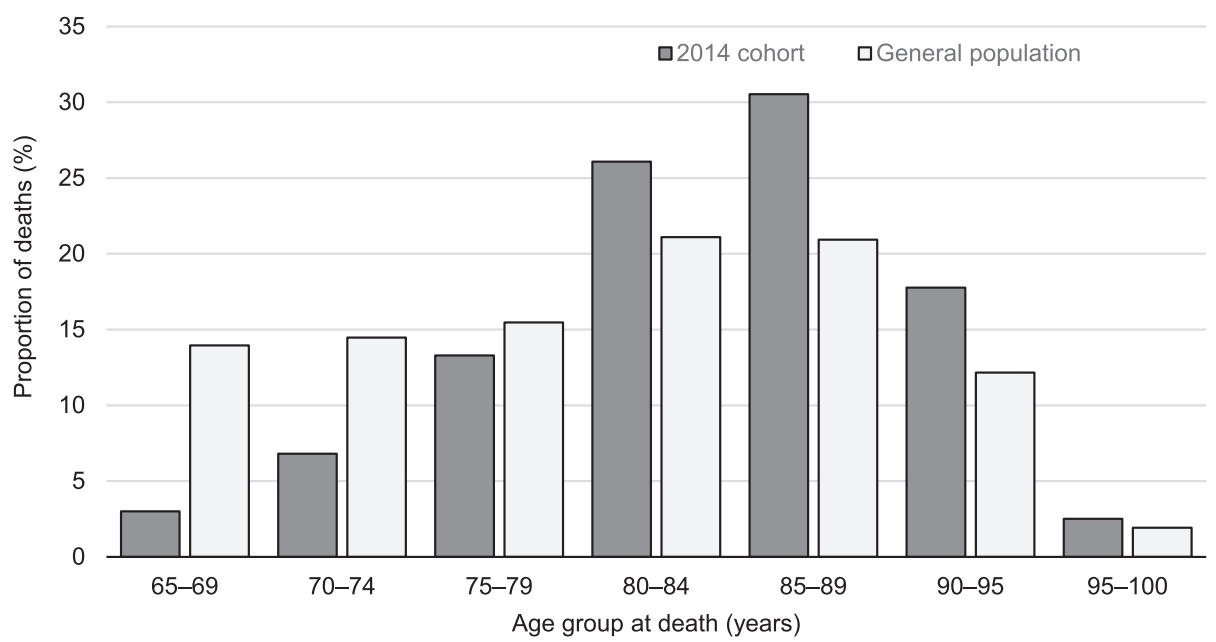

Fig. 3. Age at death in the 2014 cohort and the general population.

Table 3

Mortality of the hospitalized cohort $(n=150,311)$

\begin{tabular}{|c|c|c|c|c|c|c|c|}
\hline & $\begin{array}{l}\text { Any } \\
\text { dementia }\end{array}$ & $\mathrm{AD}$ & $\mathrm{VaD}$ & Unspecified & DLB & PDD & FTD \\
\hline \multicolumn{8}{|l|}{ Survival rate (\%) } \\
\hline 1-year & 45 & 49 & 42 & 46 & 65 & 52 & 66 \\
\hline 5-year & 16 & 18 & 14 & 16 & 36 & 20 & 33 \\
\hline $\begin{array}{l}\text { Estimated survival } \\
\text { time, median days } \\
(95 \% \mathrm{CI})\end{array}$ & $\begin{array}{l}264 \\
(259-269)\end{array}$ & $\begin{array}{l}359 \\
(346-372)\end{array}$ & $\begin{array}{l}205 \\
(198-212)\end{array}$ & $\begin{array}{l}276 \\
(264-288)\end{array}$ & $\begin{array}{l}1001 \\
(860-1142)\end{array}$ & $\begin{array}{l}414 \\
(345-483)\end{array}$ & $\begin{array}{l}948 \\
(796-1100)\end{array}$ \\
\hline \multicolumn{8}{|l|}{$\mathrm{HR}(95 \% \mathrm{CI})$} \\
\hline Model 0 & NA & Reference & $\begin{array}{l}1.16 \\
(1.14-1.18)^{* *}\end{array}$ & $\begin{array}{l}1.07 \\
(1.05-1.09)^{* *}\end{array}$ & $\begin{array}{l}0.62 \\
(0.58-0.67)^{* *}\end{array}$ & $\begin{array}{l}0.95 \\
(0.89-1.02)\end{array}$ & $\begin{array}{l}0.63 \\
(0.58-0.69)^{* *}\end{array}$ \\
\hline Model 1 & & & $\begin{array}{l}1.05 \\
(1.03-1.06)^{* *}\end{array}$ & $\begin{array}{l}0.99 \\
(0.97-1.01)\end{array}$ & $\begin{array}{l}0.65 \\
(0.60-0.70)^{* *}\end{array}$ & $\begin{array}{l}0.96 \\
(0.90-1.03)\end{array}$ & $\begin{array}{l}0.63 \\
(0.58-0.68)^{* *}\end{array}$ \\
\hline Model 2 & & & $\begin{array}{l}1.04 \\
(1.03-1.06)^{* *}\end{array}$ & $\begin{array}{l}1.00 \\
(0.98-1.02) \\
\end{array}$ & $\begin{array}{l}0.66 \\
(0.61-0.72)^{* *}\end{array}$ & $\begin{array}{l}0.98 \\
(0.92-1.05) \\
\end{array}$ & $\begin{array}{l}0.62 \\
(0.57-0.68)^{* *}\end{array}$ \\
\hline
\end{tabular}

$\mathrm{AD}$, Alzheimer's disease; CI, confidence interval; HR, hazard ratio; VaD, vascular dementia; DLB, dementia with Lewy bodies; PDD, Parkinson's disease dementia; FTD, frontotemporal dementia. Model 0: not adjusted; Model 1: adjusted for age, sex and Charlson comorbidity index; Model 2: adjusted for age, sex, Charlson comorbidity index, type of facility, region, civil status, reason for admission and planned care. ${ }^{* *} p<0.001$. Survival rates are derived from life tables. Survival time was estimated with Kaplan-Meier method. Hazard ratios are derived from Cox regression for the association of different dementia disorders with all-cause mortality, relative to Alzheimer's disease.

from 1994 to 2014. Individuals with dementia had three times the mortality than general population. VaD was the most prevalent type of dementia disorder, occurring even more frequently than $\mathrm{AD}$, and was associated with a higher risk of death when compared to $\mathrm{AD}$. The unusually high share of $\mathrm{VaD}$ patients is probably related to the common overdiagnosis of vascular dementia versus other causes of dementia. This study is important in the context of the ongoing development of the new national strategy for dementia in the Czech Republic as it contributes to filling the knowledge gap about epidemiological situation surrounding dementia.
The growing intensity of dementia hospitalizations cannot be explained by population aging, because our results are adjusted for age. It might be explained by either an increase in the prevalence of dementia or its more frequent detection. Another contributing factor is a slightly growing readmission rate (data not presented in tables). Higher prevalence may be due to increased incidence of dementia or improved survival of affected individuals. Several authors have recently pointed toward declining incidence of dementia in the USA and Western Europe, while evidence about countries in CEE has been largely lacking [28, 29]. As Seblova et al. recently suggested that the age-specific 
Table 4

Sensitivity analyses

\begin{tabular}{|c|c|c|c|c|c|c|c|}
\hline & $\mathrm{AD}$ & $\mathrm{VaD}$ & Unspecified & DLB & PDD & FTD & Mixed \\
\hline Sensitivity analysis 1 & Reference & & & & & & \\
\hline Model 0 & & $\begin{array}{l}1.16 \\
(1.14-1.17)^{* *}\end{array}$ & $\begin{array}{l}1.06 \\
(1.04-1.08)^{* *}\end{array}$ & $\begin{array}{l}0.61 \\
(0.56-0.66)^{* *}\end{array}$ & $\begin{array}{l}0.94 \\
(0.88-1.00)\end{array}$ & $\begin{array}{l}0.62 \\
(0.56-0.67)^{* *}\end{array}$ & $\begin{array}{l}1.25 \\
(1.21-1.29)^{* *}\end{array}$ \\
\hline Model 1 & & $\begin{array}{l}1.04 \\
(1.03-1.06)^{* *}\end{array}$ & $\begin{array}{l}0.98 \\
(0.96-1.00)^{*}\end{array}$ & $\begin{array}{l}0.63 \\
(0.58-0.69)^{* *}\end{array}$ & $\begin{array}{l}0.95 \\
(0.89-1.02)\end{array}$ & $\begin{array}{l}0.61 \\
(0.56-0.67)^{* *}\end{array}$ & $\begin{array}{l}1.21 \\
(1.17-1.25)^{* *}\end{array}$ \\
\hline Model 2 & & $\begin{array}{l}1.04 \\
(1.03-1.06)^{* *}\end{array}$ & $\begin{array}{l}0.99 \\
(0.97-1.01)\end{array}$ & $\begin{array}{l}0.65 \\
(0.60-0.70)^{* *}\end{array}$ & $\begin{array}{l}0.97 \\
(0.91-1.04)\end{array}$ & $\begin{array}{l}0.61 \\
(0.56-0.66)^{* *}\end{array}$ & $\begin{array}{l}1.21 \\
(1.17-1.26)^{* *}\end{array}$ \\
\hline \multicolumn{8}{|l|}{ Sensitivity analysis 2} \\
\hline Model 0 & & $\begin{array}{l}1.16 \\
(1.14-1.18)^{* *}\end{array}$ & $\begin{array}{l}1.07 \\
(1.05-1.09)^{* *}\end{array}$ & $\begin{array}{l}0.62 \\
(0.58-0.67)^{* *}\end{array}$ & $\begin{array}{l}0.95 \\
(0.89-1.01)\end{array}$ & $\begin{array}{l}0.63 \\
(0.58-0.69)^{* *}\end{array}$ & l \\
\hline Model 1 & & $\begin{array}{l}1.04 \\
(1.03-1.06)^{* *}\end{array}$ & $\begin{array}{l}0.99 \\
(0.97-1.01)\end{array}$ & $\begin{array}{l}0.65 \\
(0.60-0.70)^{* *}\end{array}$ & $\begin{array}{l}0.96 \\
(0.90-1.03)\end{array}$ & $\begin{array}{l}0.63 \\
(0.58-0.68)^{* *}\end{array}$ & I \\
\hline Model 2 & & $\begin{array}{l}1.04 \\
(1.03-1.06)^{* *}\end{array}$ & $\begin{array}{l}1.00 \\
(0.98-1.02)\end{array}$ & $\begin{array}{l}0.66 \\
(0.61-0.72)^{* *}\end{array}$ & $\begin{array}{l}0.98 \\
(0.92-1.05)\end{array}$ & $\begin{array}{l}0.62 \\
(0.57-0.68)^{* *}\end{array}$ & I \\
\hline \multicolumn{8}{|l|}{ Sensitivity analysis 3} \\
\hline Model 0 & & $\begin{array}{l}1.18 \\
(1.16-1.20)^{* *}\end{array}$ & $\begin{array}{l}1.10 \\
(1.08-1.12)^{* *}\end{array}$ & $\begin{array}{l}0.61 \\
(0.56-0.67)^{* *}\end{array}$ & $\begin{array}{l}0.90 \\
(0.83-0.97)^{*}\end{array}$ & $\begin{array}{l}0.62 \\
(0.56-0.68)^{* *}\end{array}$ & l \\
\hline Model 1 & & $\begin{array}{l}1.05 \\
(1.04-1.07)^{* *}\end{array}$ & $\begin{array}{l}1.01 \\
(0.99-1.03)\end{array}$ & $\begin{array}{l}0.63 \\
(0.58-0.69)^{* *}\end{array}$ & $\begin{array}{l}0.91 \\
(0.84-0.98)^{*}\end{array}$ & $\begin{array}{l}0.62 \\
(0.57-0.68)^{* *}\end{array}$ & l \\
\hline Model 2 & & $\begin{array}{l}1.06 \\
(1.04-1.07)^{* *}\end{array}$ & $\begin{array}{l}1.02 \\
(1.01-1.04)^{*}\end{array}$ & $\begin{array}{l}0.65 \\
(0.59-0.71)^{* *}\end{array}$ & $\begin{array}{l}0.93 \\
(0.86-1.00)\end{array}$ & $\begin{array}{l}0.62 \\
(0.56-0.68)^{* *}\end{array}$ & I \\
\hline
\end{tabular}

Results are hazard ratios with $95 \%$ confidence intervals for the risk of all-cause mortality in individuals with different dementia disorders. AD, Alzheimer's disease; VaD, vascular dementia; DLB, dementia with Lewy bodies; PDD, Parkinson's disease dementia; FTD, frontotemporal dementia; mixed, mixed dementia. ${ }^{*} p<0.05 ;{ }^{* *} p<0.001$. Model 0 : not adjusted; Model 1: adjusted for age, sex and Charlson comorbidity index; Model 2: adjusted for age, sex, Charlson comorbidity index, type of facility, region, civil status, reason for admission and planned care. Sensitivity analysis 1: category of mixed dementia was assigned to those who obtained multiple dementia diagnoses during their first hospitalization (AD: $n=39,167$; VaD: $n=72,438$; PDD: $n=1,258$; FTD: $n=828$; DLB: $n=918$; unspecified: $n=31,744$; mixed: $n=3,958$ ); Sensitivity analysis 2 : the highest dementia diagnosis was considered even if it was unspecified dementia (AD: $n=39,901 ;$ VaD: $n=74,166$; PDD: $n=1,302$; FTD: $n=866$; DLB: $n=977$; unspecified: $n=33,099)$; Sensitivity analysis 3: all people who have been assigned multiple dementia diagnoses during the observed period were excluded (AD: $n=34,071$; VaD: $n=65,228$; PDD: $n=1,076$; FTD: $n=696$; DLB: $n=752$; unspecified: $n=26,073$ ).

prevalence of cognitive impairment has declined during the past decade in the Czech Republic [30], it may be speculated that the incidence of dementia may have been declining in a CEE country as well. Decreasing mortality of individuals with dementia has been observed in previous studies from other countries [31].

In our study, we observed that the age of death has been gradually increasing during the studied period from 81 years in 1994 to 83.7 years in 2014 (data not presented in tables). The reason for the increased intensity of hospitalizations is not entirely clear, but we speculate that the prevalence of dementia may have risen due to improved survival of affected individuals. However, improved detection and diagnostics of dementia is another likely explanation of the results. It is estimated that the share of people with dementia receiving treatment in the Czech Republic increased from 9\% in 2004 [32] to $26 \%$ in 2012 [33]. We speculate that increased awareness of the dementia syndrome among physicians contributed to its better detection and therefore to more frequent treatment rates. In addition, we cannot exclude a possibility that the practice of admitting people with dementia to the hospital had changed during the studied years and that specifically in the recent years patients with dementia were more likely to be admitted than in the past.

We found that mortality of people with dementia exceeds three times the mortality of the general population, which is in line with findings from other countries [34]. The mortality nevertheless appears to be larger than in Western European countries-while we found the survival rate one year after first hospitalization to be $45 \%$ and five years after it $16 \%$, a Dutch register-based study of a similar cohort of inpatients reported 57\% and 29\%, respectively [34]. This may follow from differences in dementia diagnosis and treatment. As shown by the Czech Institute of Health Information and Statistics and the Czech Alzheimer Society [33], most dementia diagnoses in the Czech Republic are established only during a hospitalization taking place shortly before the individual's death. Similarly, a case study from a Czech 
psychiatric hospital reports that more than a half of the patients admitted for hospitalization had not been given a dementia diagnosis before the hospitalization despite already being in a progressed stage of the disease [35]. The lower mortality of dementia patients in Western Europe may then follow from the fact that their hospitalization starts when their health condition is still better.

Previous literature suggested that AD has the slowest course of all dementia types [36]. As in a study by Garcia-Ptacek and colleagues, the lower risk of mortality of AD patients relative to those with $\mathrm{VaD}$ persisted even when sociodemographic and clinical covariates were accounted for [36]. Our study supports these findings as well, however, we observed that individuals with DLB and FTD have lower risk of death than $\mathrm{AD}$, which contradicts results by GarciaPtacek. Different diagnostic and coding practices may likely explain these results. Our study is in accord with international evidence that the most common causes of death of individuals with dementia are cardiovascular diseases and that only a minority of patients have a record of dementia on a death certificate [24]. However, the fact that most people with dementia were diagnosed with $\mathrm{VaD}$, while the $\mathrm{AD}$ diagnosis appeared only in about a quarter of cases, contradicts the foreign evidence, as most studies show that $\mathrm{AD}$ is the most common type of dementia [13, 23, 37]. This may be because individuals with $\mathrm{VaD}$ are possibly overrepresented in our cohort with respect to those with AD for the following two reasons. First, individuals with $\mathrm{VaD}$ might get hospitalized more frequently because they are affected by more comorbidities [38]. Second, VaD may be more easily diagnosed as a consequence of clear cerebrovascular diseases, while signs of $\mathrm{AD}$ may be still falsely considered as normal consequences of aging by physicians not specialized in diagnosing dementia. Nevertheless, it cannot be ruled out that this is a true finding and that $\mathrm{VaD}$ was the most common dementia disorder in the Czech Republic between 1994 and 2014. The high occurrence of $\mathrm{VaD}$ may then be a consequence of a high exposure of the population to cardiovascular risk factors over the life-course of an individual. CEE has been well-known for high exposure to cardiovascular risks during the second part of the 20th century $[39,40]$. However, we noted a trend that the intensity of hospitalizations for $\mathrm{AD}$ has increased to a greater extent than for $\mathrm{VaD}$ and we may expect that $\mathrm{AD}$ will soon become the most frequent type of dementia disorders.
Future research should focus on two understudied groups of people with dementia that are not included in our study. First, there are people with dementia who receive only primary care and outpatient specialist care. The Institute of Health Information and Statistics has recently established a new Register of Reimbursed Health Services, which includes all treatment and medication reimbursed by a health care insurer. While we do not have access to this register, preliminary (unpublished) data shows that, in 2015, health care insurers reimbursed inpatient and outpatient treatment of dementia or dementia medication for about 92,480 individuals older than 50 years. In comparison, our 2014 cohort (including only people between 65 and 100 years of age) counts 41,913 individuals. The new register will hopefully allow future research of the Czech dementia population to incorporate outpatient cases, understand the difference in characteristics and mortality between individuals receiving outpatient and inpatient care, and validate the accuracy of comorbidities listed in the NRHP. Second, there are people with undetected dementia, about which we have currently no information. Previous study estimated that barely a half of dementia cases are detected by the Swedish registers of inpatient and outpatient care and causes of death [41]. Other analyses report likelihood of dementia detection ranging between $26 \%$ and $55 \%$ in patient registers and between $28 \%$ and $53 \%$ in death registers [42-45].

This study has several limitations related to the source of data used for this study and to the low accuracy in diagnosing dementia. It is likely that there is a variation to what degree dementia is actually considered at hospitalizations and death certificates, and also that mild cases are not detected. The results are probably subject to selection bias with respect to the entire Czech dementia population. People with dementia who have been hospitalized presumably show higher mortality than those who have not. Further, validation of the diagnoses of dementia has not been performed. Studies from other countries suggest that misclassification of different dementia disorders in national patient registers is common [41]. This likely holds for our study as well, given the fact that $15 \%$ of people in our sample were diagnosed with two or more different dementia disorders during the observed period (data not presented in tables). The high misclassification of dementia disorders in the present study may underestimate clinical differences between different types of dementia that were found more pronounced in previous studies [26, 38, 46]. 
The present study has nevertheless also many strengths. It encompasses all dementia hospitalizations and registered deaths in the Czech Republic in 21 years. It provides information about the characteristics and mortality of the Czech dementia population, distinguishing between different types of dementia disorders. To the best of our knowledge, it is the very first study of its kind for a CEE country. These countries have been largely underrepresented in studies on mental disorders [47]; however, existing evidence shows that older adults in CEE have a higher burden of brain disorders compared to their counterparts in Western Europe and Scandinavia [48-50]. We believe that the study will prove exceptionally useful in the development of Czech health and social care for dementia and that it will be of great value also to other post-communist CEE countries.

\section{ACKNOWLEDGMENTS}

The authors are grateful to Vaclav Sladek for his help with data management. This study was supported by the grant No. F4/38/2018 from the Internal Grant Agency of the University of Economics, Prague.

Authors' disclosures available online (https:// www.j-alz.com/manuscript-disclosures/19-1117r3).

\section{REFERENCES}

[1] Arltová M, Langhamrová J, Langhamrová J (2013) Development of life expectancy in the Czech Republic in years 1920-2010 with an outlook to 2050. Prague Economic Papers 22, 125-143.

[2] Czech Statistical Office (2018) Czech Demographic Handbook 2017, Czech Statistical Office, Prague.

[3] Winblad B, Amouyel P, Andrieu S, Ballard C, Brayne C, Brodaty H, Cedazo-Minguez A, Dubois B, Edvardsson D, Feldman H (2016) Defeating Alzheimer's disease and other dementias: A priority for European science and society. Lancet Neurol 15, 455-532.

[4] Prince M, Comas-Herrera A, Knapp M, Guerchet Ml, Karagiannidou M (2016) World Alzheimer Report 2016. Improving healthcare for people living with dementia: Coverage, quality and costs now and in the future. Alzheimer's Disease International, London.

[5] Broulikova HM, Sladek V, Arltova M, Cerny J (2018) The potential impact of Alzheimer's disease early treatment on societal costs of care in Czechia: A simulation approach. J Ment Health Policy Econ 21, 147-161.

[6] Czech Statistical Office (2018) Average wages - 4th quarter of 2017, Czech Statistical Office, Prague.

[7] World Health Organization (2012) Dementia: A public health priority, World Health Organization.

[8] Seiler S, Schmidt H, Lechner A, Benke T, Sanin G, Ransmayr G, Lehner R, Dal-Bianco P, Santer P, Linortner P (2012) Driving cessation and dementia: Results of the prospective registry on dementia in Austria (PRODEM). PLoS One 7, e52710.

[9] Choi SH, Kim S, Han S-H, Na DL, Kim D-K, Cheong H-K, Lee J-H, Kim SY, Hong CH, Moon SY (2012) Neurologic signs in relation to cognitive function in subcortical ischemic vascular dementia: A CREDOS (Clinical Research Center for Dementia of South Korea) study. Neurol Sci 33, 839-846.

[10] Johannsen P, Jørgensen K, Kørner A, Elmo EG, Lauesen LB, Utzon J (2011) Development of a dementia assessment quality database. Aging Mental Health 15, 40-46.

[11] Persson K, Brækhus A, Selbæk G, Kirkevold Ø, Engedal K (2015) Burden of care and patient's neuropsychiatric symptoms influence carer's evaluation of cognitive impairment. Dement Geriatr Cogn Disord 40, 256-267.

[12] Garre-Olmo J, Flaqué M, Gich J, Pulido TO, Turbau J, Vallmajo N, Viñas M, López-Pousa S (2009) A clinical registry of dementia based on the principle of epidemiological surveillance. BMC Neurol 9, 5 .

[13] Religa D, Fereshtehnejad S-M, Cermakova P, Edlund A-K, Garcia-Ptacek S, Granqvist N, Hallbäck A, Kåwe K, Farahmand B, Kilander L (2015) SveDem, the Swedish Dementia Registry-A tool for improving the quality of diagnostics, treatment and care of dementia patients in clinical practice. PloS One 10, e0116538.

[14] Anthony S, Pradier C, Chevrier R, Festraëts J, Tifratene K, Robert P (2014) The French National Alzheimer database: A fast growing database for researchers and clinicians. Dement Geriatr Cogn Disord 38, 271-280.

[15] Krysinska K, Sachdev PS, Breitner J, Kivipelto M, Kukull W, Brodaty H (2017) Dementia registries around the globe and their applications: A systematic review. Alzheimers Dement 13, 1031-1047.

[16] Wu Y-T, Fratiglioni L, Matthews FE, Lobo A, Breteler MMB, Skoog I, Brayne C (2016) Dementia in western Europe: Epidemiological evidence and implications for policy making. Lancet Neurol 15, 116-124.

[17] World Health Organization (2007) International classification of diseases and related health problems, 10th revision.

[18] Charlson ME, Pompei P, Ales KL, MacKenzie CR (1987) A new method of classifying prognostic comorbidity in longitudinal studies: Development and validation. J Chronic Dis 40, 373-383.

[19] Bannay A, Chaignot C, Blotière P-O, Basson M, Weill A, Ricordeau P, Alla F (2016) The best use of the Charlson comorbidity index with electronic health care database to predict mortality. Med Care 54, 188-194.

[20] Cermakova P, Nelson M, Secnik J, Garcia-Ptacek S, Johnell K, Fastbom J, Kilander L, Winblad B, Eriksdotter M, Religa D (2017) Living alone with Alzheimer's disease: Data from SveDem, the Swedish Dementia Registry. J Alzheimers Dis 58, 1265-1272.

[21] Sundararajan V, Henderson T, Perry C, Muggivan A, Quan H, Ghali WA (2004) New ICD-10 version of the Charlson comorbidity index predicted in-hospital mortality. J Clin Epidemiol 57, 1288-1294.

[22] Czech Statistical Office (2018) Life tables for the CR since 1920, Czech Statistical Office, Prague.

[23] Subic A, Cermakova P, Religa D, Han S, von Euler M, Kareholt I, Johnell K, Fastbom J, Bognandi L, Winblad B, Kramberger MG, Eriksdotter M, Garcia-Ptacek S (2018) Treatment of atrial fibrillation in patients with dementia: A cohort study from the Swedish Dementia Registry. $J$ Alzheimers Dis 61, 1119-1128. 
[24] Garcia-Ptacek S, Kåreholt I, Cermakova P, Rizzuto D, Religa D, Eriksdotter M (2016) Causes of death according to death certificates in individuals with dementia: A cohort from the Swedish Dementia Registry. J Am Geriatr Soc 64, e137-e142.

[25] Cermakova P, Szummer K, Johnell K, Fastbom J, Winblad B, Eriksdotter M, Religa D (2017) Management of acute myocardial infarction in patients with dementia: Data from SveDem, the Swedish Dementia Registry. J Am Med Dir Assoc 18, 19-23.

[26] Enache D, Fereshtehnejad SM, Kareholt I, Cermakova P, Garcia-Ptacek S, Johnell K, Religa D, Jelic V, Winblad B, Ballard C, Aarsland D, Fastbom J, Eriksdotter M (2016) Antidepressants and mortality risk in a dementia cohort: Data from SveDem, the Swedish Dementia Registry. Acta Psychiatr Scand 134, 430-440.

[27] Subic A, Zupanic E, von Euler M, Norrving B, Cermakova P, Religa D, Winblad B, Kramberger MG, Eriksdotter M, Garcia-Ptacek S (2018) Stroke as a cause of death in death certificates of patients with dementia: A cohort study from the Swedish Dementia Registry. Curr Alzheimer Res 15, 1322-1330.

[28] Wu Y-T, Beiser AS, Breteler MM, Fratiglioni L, Helmer C, Hendrie HC, Honda H, Ikram MA, Langa KM, Lobo A (2017) The changing prevalence and incidence of dementia over time-current evidence. Nat Rev Neurol 13, 327.

[29] Schrijvers EM, Verhaaren BF, Koudstaal PJ, Hofman A, Ikram MA, Breteler MM (2012) Is dementia incidence declining? Trends in dementia incidence since 1990 in the Rotterdam Study. Neurology 78, 1456-1463.

[30] Seblova D, Brayne C, Machu V, Kuklova M, Kopecek M, Cermakova P (2019) Changes in cognitive impairment in the Czech Republic. J Alzheimers Dis 72, 693-701.

[31] Qiu C, von Strauss E, Bäckman L, Winblad B, Fratiglioni L (2013) Twenty-year changes in dementia occurrence suggest decreasing incidence in central Stockholm, Sweden. Neurology 80, 1888-1894.

[32] Waldemar G, Phung KT, Burns A, Georges J, Hansen FR, Iliffe S, Marking C, Rikkert MO, Selmes J, Stoppe G (2007) Access to diagnostic evaluation and treatment for dementia in Europe. Int J Geriatr Psychiatry 22, 47-54.

[33] Mátl O, Mátlová M, Holmerová I (2016) Zpráva o stavu demence 2016, Česká alzheimerovská společnost, Praha.

[34] Van De Vorst IE, Vaartjes I, Geerlings MI, Bots ML, Koek HL (2015) Prognosis of patients with dementia: Results from a prospective nationwide registry linkage study in the Netherlands. BMJ Open 5, e008897.

[35] Luzny J, Holmerova I, Petr W, Ondrejka I (2014) Dementia still diagnosed too late-Data from the Czech Republic. Iran J Public Health 43, 1436.

[36] Garcia-Ptacek S, Farahmand B, Kåreholt I, Religa D, Cuadrado M, Eriksdotter M (2014) Mortality risk after dementia diagnosis by dementia type and underlying factors: A cohort of 15,209 patients based on the Swedish Dementia Registry. J Alzheimers Dis 41, 466-477.
[37] Cermakova P, Fereshtehnejad SM, Johnell K, Winblad B, Eriksdotter M, Religa D (2014) Cardiovascular medication burden in dementia disorders: A nationwide study of 19,743 dementia patients in the Swedish Dementia Registry. Alzheimers Res Ther 6, 34.

[38] Cermakova P, Johnell K, Fastbom J, Garcia-Ptacek S, Lund LH, Winblad B, Eriksdotter M, Religa D (2015) Cardiovascular diseases in $\sim 30,000$ patients in the Swedish Dementia Registry. J Alzheimers Dis 48, 949-958.

[39] Bobak M, Marmot M (1996) East-West mortality divide and its potential explanations: Proposed research agenda. BMJ 312, 421-425.

[40] Peasey A, Bobak M, Kubinova R, Malyutina S, Pajak A, Tamosiunas A, Pikhart H, Nicholson A, Marmot M (2006) Determinants of cardiovascular disease and other non-communicable diseases in Central and Eastern Europe: Rationale and design of the HAPIEE study. BMC Public Health 6, 255.

[41] Rizzuto D, Feldman AL, Karlsson IK, Dahl Aslan AK, Gatz M, Pedersen NL (2018) Detection of dementia cases in two Swedish health registers: A validation study. J Alzheimers Dis 61, 1301-1310.

[42] Dahl A, Berg S, Nilsson SE (2007) Identification of dementia in epidemiological research: A study on the usefulness of various data sources. Aging Clin Exp Res 19, 381-389.

[43] Jin Y-P, Gatz M, Johansson B, Pedersen NL (2004) Sensitivity and specificity of dementia coding in two Swedish disease registries. Neurology 63, 739-741.

[44] Solomon A, Ngandu T, Soininen H, Hallikainen MM, Kivipelto M, Laatikainen T (2014) Validity of dementia and Alzheimer's disease diagnoses in Finnish national registers. Alzheimers Dement 10, 303-309.

[45] Perera G, Stewart R, Higginson IJ, Sleeman KE (2016) Reporting of clinically diagnosed dementia on death certificates: Retrospective cohort study. Age Ageing 45, 668-673.

[46] Cermakova P, Lund LH, Fereshtehnejad SM, Johnell K, Winblad B, Dahlstrom U, Eriksdotter M, Religa D (2015) Heart failure and dementia: Survival in relation to types of heart failure and different dementia disorders. Eur J Heart Fail 17, 612-619.

[47] Winkler P, Formanek T, Mlada K, Cermakova P (2018) The CZEch Mental health Study (CZEMS): Study rationale, design, and methods. Int J Methods Psychiatr Res 27, e1728.

[48] Cermakova P, Formanek T, Kagstrom A, Winkler P (2018) Socioeconomic position in childhood and cognitive aging in Europe. Neurology 91, e1602-e1610.

[49] Formanek T, Kagstrom A, Winkler P, Cermakova P (2019) Differences in cognitive performance and cognitive decline across European regions: A population-based prospective cohort study. Eur Psychiatry 58, 80-86.

[50] Horackova K, Kopecek M, Machu V, Kagstrom A, Aarsland D, Motlova LB, Cermakova P (2019) Prevalence of latelife depression and gap in mental health service use across European regions. Eur Psychiatry 57, 19-25. 